\title{
THỰC TRẠG DINH DƯỠNG Ở HỌC SINH LỚP 10 TẠI TRƯỜNG TRUNG HỌC PHỔ THÔNG GANG THÉP THÁI NGUYÊN NĂM 2020
}

\section{TÓM TẮT}

Đặt vấn đề: Học sinh trung học phổ thông là đối tương cần quan tâm vì đây là lực lượng lao động chính sau này, lứa tuổi này là lứa tuổi tiếp tục hoàn thiện về thể chất. Chính vì vậy chế độ dinh dưỡng khổng hợp lý có thể dẫn đến những ảnh hưởng lâu dài tới sức khỏe bệnh tật, khả năng học tập và giảm sút khả năng lao động sau này. Mục tiêu: Đánh giá tình trạng dinh dưỡng của học sinh lớp 10 trường trung học phổ thông Gang Thép, thành phố Thái Nguyên năm 2020. Đối tượng và phương pháp nghiên cứu: Nghiên cứu được tiến hành theo phương pháp mô tả, thiết kế cắt ngang trên toàn bộ học sinh lớp 10 trường trung học phổ thông Gang Thép, thành phố Thái Nguyên. Kết quả nghiên cứu: Tỷ lệ học sinh bị suy dinh dưỡng thể thấp còi chiếm khá cao $12,7 \%$ : Suy dinh dưỡng mức độ vừa chiếm chủ yếu $12,0 \%$, suy dinh dưỡng mức độ nặng chỉ chiếm tỷ lệ $0,7 \%$. Tỷ lệ suy dinh dưỡng thấp cời ở học sinh nữ $(13,0 \%)$ cao hơn hoc sinh nam $(12,2 \%)$, tuy nhiên sự khác biệt không có ý nghĩa thống kê giữa tỷ lệ suy dinh dưỡng thể thấp còi giữa hai giới ( $p$ > $0,05)$. Tỷ lệ suy dinh dưỡng gây còm của học sinh chiếm $6,9 \%$. Hoc sinh nữ $(7,5 \%)$ có tỷ lê sưy dinh dưỡng cao hơn học sinh nam $(6,1 \%)$. Tỷ lệ thửa cân, béo phì chiếm $13,8 \%$. Trong đó tỷ lệ thửa cân, béo phì ở học sinh nam $(17,9 \%)$ cao hơn rõ rệt ở học sinh nữ $(10,6 \%)$.

Tứ khoá: Suy dinh dương, thấp còi, gày còm, thừa cân, béo phì, trường trung học phổ thông, Gang Thép, thành phố Thái Nguyên.

\section{SUMMARY}

\section{THE NUTRITIONAL STATUS OF GRADE 10 STUDENTS AT THAI NGUYEN GANG THEP HIGH SCHOOL IN 2020}

Background: High school students are the object of concern because this is the main workforce in the future, this age is the age to continue to improve physically. Therefore, improper nutrition can lead to long-term effects on health, disease, learning ability and reduced ability to work later. Objective: To evaluate the nutritional status of 10th grade students at Gang Thep High School, Thai Nguyen city in 2020. Research subjects and methods: The study was conducted by descriptive method, cross-sectional design on all 10th grade students of Gang Thep High School, Thai Nguyen city. Research results: The

\footnotetext{
${ }^{1}$ Trường Đại học Y Dược - Đại học Thái Nguyên Chịu trách nhiệm chính: Ngô Hồng Nhung Email: nhungtn9x@gmail.com Ngày nhận bài: 2.3.2021 Ngày phản biện khoa học: 26.4.2021 Ngày duyệt bài: 10.5.2021
}

\section{Ngô Hồng Nhung ${ }^{1}$, Trương Thị Thùy Dương ${ }^{1}$}

rate of students suffering from stunting was quite high $12.7 \%$ : Moderate malnutrition accounts for $12.0 \%$, severe malnutrition accounts for only $0.7 \%$. The rate of stunting malnutrition among female students $(13.0 \%)$ was higher than that of male students $(12.2 \%)$, but the difference was not statistically significant between the prevalence of stunting between two sexes $(p>0.05)$. The rate of malnutrition and emaciation of students accounts for $6.9 \%$. Female students $(7.5 \%)$ had a higher rate of malnutrition than male students $(6.1 \%)$. The rate of overweight and obesity accounted for $13.8 \%$. In which, the rate of overweight and obesity among male students $(17.9 \%)$ was significantly higher than that of female students $(10.6 \%)$.

Keywords: Malnutrition, stunting, emaciation, overweight, obesity, high school, Gang Thep, Thai Nguyen city.

\section{I. ĐắT VẤN ĐỀ}

Hiện nay, Việt Nam đang đối mặt với gánh nặng kép về dinh dưỡng, bên cạnh tỷ lệ suy dinh dưỡng ở trẻ em và thiếu năng lượng trường diễn ở người trưởng thành còn cao thì tỷ lệ thửa cân, béo phì đang gia tăng dẫn đến thay đổi mô hình bệnh tật và tử vong. Thừa cân/béo phì là một trong những nguy cơ chính của các bệnh mạn tính không lây như bệnh mạch vành, tăng huyết áp, đái tháo đường, bệnh sỏi mật, ung thư...

Học sinh trung học phổ thông là đối tượng cân quan tâm vì đây là lực lượng lao động chính sau này, lứa tuổi này là lứa tuổi tiếp tục hoàn thiện về thể chất. Chính vì vậy chế độ dinh dưỡng không hợp lý có thể dẫn đến những ảnh hưởng lâu dài tới sức khỏe bệnh tật, khả năng học tập và giảm sút khả năng laoo động sau này.

Ở Việt Nam, những nghiên cứu trước đây về dinh dưỡng thường tập trung vào đối tượng trẻ dưới 5 tuổi, bà mẹ có thai và cho con bú. Đối với lứa tuổi vị thành niên ở trung học phổ thông. Dữ liệu về tình trạng dinh dưỡng và sức khỏe học đường còn hạn chế. Lứa tuổi 15-18 đang trong giai đoạn vị thành niên muộn, là cơ hội cuối cùng về phát triển chiều cao của cuộc đời do đó cũng là giai đoạn sau cùng để cải thiện tình trạng dinh dưỡng của các em.

Kết quả nghiên cứu của tác giả Nguyễn Nhật Cảm, Nguyễn Thị Thi Thơ và cộng sự (2017) cho thấy: Tỷ lệ suy dinh dưỡng thể gây còm ở học sinh từ 11- 17 tuổi là 7,59\% trong đó suy dinh dưỡng gây còm nặng là $1,85 \%$, và tỷ lệ suy dinh dưỡng thể gâyy còm vừa là 5,74\% [2]. 
Kết quả nghiên cứu gần đây của tác giả Lê Trần Tuấn Anh, Nguyễn Thị Thắm và cộng sự (2021) ở học sinh trường Trung học phổ thông Lê Quý Đôn, quận Hải An, thành phố Hải Phòng cho thây có $6,4 \%$ học sinh bị suy dinh dưỡng thể thấp còi trong đó nữ học sinh bị suy dinh dưỡng thể thấp còi chiếm $6,6 \%$ cao hơn nam học sinh $(6,1 \%)[1]$.

Bên cạnh tỷ lệ suy dinh dương ở học sinh trung học phổ thông còn cao thì tỳ lệ thừa cân, béo phì ở lứa tuổi này có xu hướng gia tăng. Theo kết quả nghiên cứu của tác giả Nguyển Thị Thắm, Lê Trần Tuấn Anh và cộng sự (2021) cho thấy: Tỷ lệ TCBP ở học sinh là 17,3\%, trong đó thừa cân là $14,0 \%$, béo phì là $3,3 \%$. Tỷ lệ TCBP ở học sinh nam 25,2\% cao hơn so với học sinh nữ 11,1\% [5]. Tại Thái Nguyên, nghiên cứu về tình trạng dinh dưỡng của học sinh ở lứa tuổi học đường đặc biệt ở học sinh trung học phổ thông còn rất hạn chế.

Vì vậy chúng tôi tiến hành đề tài: "Thực trạng dinh dướng ở học sinh lớp 10 tại trường trung học phổ thông Gang Thép Thái Nguyên năm 2020". Với mục tiêu: Đánh giá tình trạng dinh dướng của học sinh lớp 10 trường trung học phổ thông Gang Thép, thành phố Thái Nguyên năm 2020.

\section{II. ĐỐI TƯợNG VÀ PHƯƠNG PHÁP NGHIÊN CứU}

2.1. Đối tượng nghiên cứu. Học sinh lớp 10 trường Trung học phổ thông Gang Thép, thành phố Thái Nguyên.

\subsection{Thời gian và địa điểm nghiên cứu}

- Thời gian: Từ tháng 01/2020 đến tháng $12 / 2020$.

- Địa điểm: Trường trung học phổ thông Gang Thép, thành phố Thái Nguyên, tỉnh Thái Nguyên.

\subsection{Thiết kế nghiên cứu}

2.3.1. Thiết kế nghiên cứu: Nghiên cứu mô tả, thiết kế cắt ngang

2.3.2. Cỡ mẫu và phương pháp chọn mẫu:

* Cõ̃ mẫu: Toàn bộ (học sinh lớp 10 trường trung học phổ thông Gang Thép, thành phố Thái Nguyên). Tổng cõ̃ mẫu $n=450$.

*Phương pháp chọn mẫu: Chọn chủ đích toàn bộ học sinh lớp 10 của trường Trung học phổ thổng Gang Thép, thành phố Thái Nguyên.

*Tiêu chuẩn lứa chọn đôi tượng nghiên cứu. Học sinh lớp 10 trường trung học phổ thông Gang Thép, thành phố Thái Nguyên tự nguyện tham gia vào nghiên cứu và có khả năng trả lời phỏng vấn.

\subsection{Chỉ số nghiên cứu} dân tộc.
- Cân nặng, chiều cao trung bình, chỉ số khối cơ thể (BMI).

- Tỷ lệ suy dinh dưỡng, mức độ suy dinh dưỡng.

- Tỷ lề thừa cân, béo phì.

\subsection{Kỹ thuật thu thập thông tin}

*Thu thập về một số chỉ số nhân trắc:

- Cân nặng: Sử dụng cân SECA của Nhật Bản

- Chiều cao: Sử dụng thước gỗ của UNICEF

*Đánh giá thừa cân, béo phì và suy dinh dưỡng: theo bảng phân loại Z-score của WHO 2007 cho trẻ từ 10 đến 19 tuổi:

- Đánh giá chỉ số Z - score chiều cao theo tuổi:

+ SDD thể thấp còi mức độ vừa: Z- score < 2 SD đến - 3SD.

+ SDD thể thấp còi mức độ nặng: Z- score < - 3SD.

+ Tình trạng dinh dương bình thường: - 2 SD $\leq Z$ - score $\leq+1$ SD.

- Đánh giá chỉ số Z - score BMI theo tuổi:

+ SDD thể gày còm mức độ vừa: $Z$ - score $<-2$ SD đến - 3SD.

+ SDD thể gày còm mức độ nặng: Z - score $<-3 \mathrm{SD}$

+ Tình trạng dinh dương bình thường: - 2 SD $\leq$ Z- score $\leq+1$ SD.

+ Thừa cân: + 1SD < Z- score < + 2 SD

+ Béo phì: Z- score $\geq+2$ SD.

2.6. Phương pháp xử lý số liệu. Số liệu được mã hóa, làm sạch và nhập trên phần mềm Epidata 3.1; xử lý trên phần mềm SPSS 20.0.

\subsection{Sai số và khống chế sai số}

- Quá trình thu thâp số liêu đều sử dụng các công cụ chuẩn (cân, thước, bộ câu hỏi), sử dụng kĩ thuật chuẩn xác, thực hiện đúng theo thường quy, tập huấn kỹ thuật và thống nhất phương pháp điêu tra trong thu thập số liệu.

- Nhóm nghiên cứu xem xét, kiểm tra lại các phiếu sau mối ngày điều tra.

\section{KẾT QUẢ NGHIÊN CỨU}

3.1. Thông tin chung của đối tượng nghiên cứu

Bảng 3.1. Thông tin chung của đối tượng nghiên cứlu

\begin{tabular}{|c|c|c|c|}
\hline \multicolumn{2}{|c|}{ Đặc điếm } & Số lượng & Tỷ lệ \% \\
\hline \multirow{3}{*}{ Giới } & Nam & 196 & 43,6 \\
\cline { 2 - 4 } & Nữ & 254 & 56,4 \\
\cline { 2 - 4 } & Tống số & $\mathbf{4 5 0}$ & $\mathbf{1 0 0}$ \\
\hline \multirow{4}{*}{$\begin{array}{c}\text { Dân } \\
\text { tộc }\end{array}$} & Kinh & 387 & 86,0 \\
\cline { 2 - 4 } & Tày & 35 & 7,8 \\
\cline { 2 - 4 } & Nùng & 23 & 5,1 \\
\cline { 2 - 4 } & Dao & 3 & 0,7 \\
\cline { 2 - 4 } & Khác & 2 & 0,4 \\
\cline { 2 - 4 } & Tống số & $\mathbf{4 5 0}$ & $\mathbf{1 0 0}$ \\
\hline
\end{tabular}


Nhận xét: Tổng số học sinh điều tra là 450 học sinh, trong đó có 254 học sinh là nữ và 196 học sinh là nam. Tỷ lệ học sinh nữ cao hơn ở nam giới với tỷ lệ lần lượt là $56,4 \%$ và $43,6 \%$. Phần lớn đối tượng nghiên cứu thuộc dân tộc
Kinh, chiếm tỷ lệ cao nhất là $86 \%$, tiếp đến là học sinh thuộc dân tộc Tày $(7,8 \%)$, dân tộc Nùng $(5,1 \%)$, chiếm tỷ lệ rất thấp $(0,7 \%)$ là học sinh thuộc dân tộc Dao và còn lại dân tộc khác chỉ chiếm 0,4\%.

3.2. Tình trạng dinh dưỡng của học sinh khối 10 của Trường THPT Gang Thép, thành phố Thái Nguyền

Bảng 3.2. Cân năng, chiều cao và chỉ số BMI trung bình của học sinh theo giới ở Trường THPT Gang Thép, thành phô Thái Nguyên

\begin{tabular}{|c|c|c|c|c|}
\hline Giới & $\mathbf{N a m}\left(\overline{\boldsymbol{X}}_{ \pm \mathrm{SD}}\right)$ & $\mathbf{N}$ điểm $\left.\overline{\boldsymbol{X}}_{ \pm \mathrm{SD}}\right)$ & Chung $\left.\boldsymbol{(}_{ \pm \mathrm{SD}}\right)$ & $\mathbf{p}$ \\
\hline Cân nặng trung bình $(\mathrm{kg})$ & $55,1 \pm 12,7$ & $47,5 \pm 7,7$ & $50,8 \pm 10,8$ & $<0,05$ \\
\hline Chiều cao trung bình $(\mathrm{cm})$ & $167,5 \pm 6,7$ & $157,3 \pm 6,4$ & $161,7 \pm 8,2$ & $<0,05$ \\
\hline Chỉ số BMI trung bình $\left(\mathrm{kg} / \mathrm{m}^{2}\right)$ & $19,6 \pm 3,9$ & $19,2 \pm 2,9$ & $19,4 \pm 3,4$ & $>0,05$ \\
\hline
\end{tabular}

Nhận xét: Cân nặng, chiêu cao và BMI trung bình của học sinh trường THPT Gang Thép, thành phố Thái Nguyên lần lượt là: $50,8 \pm 10,8,161,7 \pm 8,2$ và $19,4 \pm 3,4$. Trong đó: Cân nặng, chiêu cao và $B M I$ trung bình của nam học sinh $(55,1 \pm 12,7 ; 167,5 \pm 6,7$ và19,6 $\pm 3,9)$ cao hớn nữ học sinh $(47,5 \pm 7,7 ; 157,3 \pm 6,4$ và 19,2 $\pm 2,9)$. Sự khác biệt về chỉ số cân nặng và chiều cao trung bình giữa hai giới có ý nghĩa thống kê với $p<0,05$. Tuy nhiên sự khác biệt về chỉ số BMI trung bình giữa hai giới không có ý nghĩa thống kê với p > 0,05.

Bảng 3.3. Tình trạng suy dinh dưỡng thể thấp còi (chiều cao/tuổi thấp) của học sinh khôi 10 của Trường THPT Gang Thép, thành phố Thái Nguyên

\begin{tabular}{|c|c|c|c|c|c|c|}
\hline \multirow{3}{*}{ Giới } & \multicolumn{6}{|c|}{ Tình trạng suy dinh dưỡng } \\
\hline & \multicolumn{2}{|c|}{$\begin{array}{c}\text { SDD mức độ vừa } \\
\text { (CC/tuổi < - 2SD đên - 3SD) }\end{array}$} & \multicolumn{2}{|c|}{$\begin{array}{l}\text { SDD mức độ nắng } \\
\text { (CC/tuổi < - } 3 \text { S̃D) }\end{array}$} & \multicolumn{2}{|c|}{ Chung } \\
\hline & $\mathbf{S L}$ & $\%$ & SL & $\%$ & $\mathbf{S L}$ & $\%$ \\
\hline $\operatorname{Nam}(S L=196)$ & 23 & 11,7 & 1 & 0,5 & 24 & 12,2 \\
\hline $\mathrm{Nữ}(\mathrm{SL}=254)$ & 31 & 12,2 & 2 & 0,8 & 33 & 13,0 \\
\hline $\mathrm{p}$ & \multicolumn{2}{|c|}{$>0,05$} & \multicolumn{2}{|c|}{$>0,05$} & \multicolumn{2}{|c|}{$>0,05$} \\
\hline Chung $(n=450)$ & 54 & 12,0 & 3 & 0,7 & 57 & 12,7 \\
\hline
\end{tabular}

Nhận xét: Tỷ lệ học sinh bị suy dinh dưỡng thấp còi chiếm khá cao $12,7 \%$ trong đó suy dinh dưỡng mức độ vửa chiếm chủ yếu $12,0 \%$, suy dinh dưỡng mức độ nặng chỉ chiếm tỷ lệ $0,7 \%$ trong đó suy dinh dương thấp còi mức độ vừa và nặng ở học sinh nữ (12,2\% và $0,8 \%)$ cao hơn học sinh nam $(11,7 \%$ và $0,5 \%)$, tuy nhiên sự khác biệt không có ý nghĩa thống kê giữa tỷ lệ suy dinh dưỡng thể thấp còi giữa hai giới $(\mathrm{p}>0,05)$.

Bảng 3.4. Phân loại tình trạng dinh dưỡng dựa vào chỉ số BMI theo giới của học sinh khôi 10 của Trường THPT Gang Thép, thành phố Thái Nguyên

\begin{tabular}{|c|c|c|c|c|c|c|}
\hline \multirow[b]{2}{*}{ Giới } & \multicolumn{2}{|c|}{$\begin{array}{l}\text { DD (BMI/tuối }<-2 \\
\text { SD) }\end{array}$} & \multicolumn{2}{|c|}{$\begin{array}{c}\text { Bình thường (BMI/tuối từ } \\
\text { - 1SD đến - } 2 \text { SD) }\end{array}$} & \multicolumn{2}{|c|}{$\begin{array}{l}\text { Thừa cân, béo phì } \\
\text { (BMI/tuổi > + } 1 \text { SD) }\end{array}$} \\
\hline & $\mathbf{S L}$ & $\%$ & $\mathbf{S L}$ & $\%$ & SL & $\%$ \\
\hline \begin{tabular}{|l}
$\operatorname{Nam}(\mathrm{SL}=196)$ \\
\end{tabular} & 12 & 6,1 & 149 & 76,0 & 35 & 17,9 \\
\hline Nữ $(S L=254)$ & 19 & 7,5 & 208 & 81,9 & 27 & 10,6 \\
\hline Chung $(n=450)$ & 31 & 6,9 & 357 & 79,3 & 62 & 13,8 \\
\hline
\end{tabular}

Nhận xét: Tỷ lệ suy dinh dưỡng thể gầy còm của học sinh khối 10 Trường THPT Gang Thép Thái Nguyên chiếm 6,9\% trong đó học sinh nữ $(7,5 \%)$ có tỷ lệ suy dinh dưỡng cao hơn học sinh nam $(6,1 \%)$. Tỳ lệ thừa cân, béo phì chiếm $13,8 \%$ trong đó tỳ lệ thừa cân, béo phì ở học sinh nam $(17,9 \%)$ cũng cao hơn rõ rệt học sinh nữ $(10,6 \%)$.

\section{BÀN LUÂ̂N}

Tổng số học sinh điều tra là 450 học sinh, trong đó có 254 học sinh là nữ và 196 học sinh là nam. Tỷ lệ học sinh nữ cao hơn ở nam giới với tỷ lệ lần lượt là $56,4 \%$ và $43,6 \%$. Phần lớn đối tượng nghiển cứu thuộc dân tộc Kinh, chiếm tỷ lệ cao nhất là $86 \%$, tiếp đến là học sinh thuộc dân tộc Tày $(7,8 \%)$, dân tộc Nùng $(5,1 \%)$, chiếm tỷ lệ rất thấp $(0,7 \%)$ là học sinh thuộc dân tộc Dao và còn lại dân tộc khác chỉ chiếm 0,4\% (bảng 3.1).

Kết quả ở bảng 3.2 cho thấy: Cân nặng, chiều cao và $\mathrm{BMI}$ trung bình của học sinh trường 
THPT Gang Thép, thành phố Thái Nguyên lần lượt là: $50,8 \pm 10,8,161,7 \pm 8,2$ và 19,4 $\pm 3,4$. Trong đó cân nặng, chiều cao và BMI trung bình của nam học sinh $(55,1 \pm 12,7 ; 167,5 \pm 6,7$ và19,6 $\pm 3,9)$ cao hơn nữ học sinh $(47,5 \pm 7,7$; $157,3 \pm 6,4$ và 19,2 $\pm 2,9)$. Sự khác biệt về chỉ số cân nặng và chiều cao trung bình giữa hai giới có ý nghĩa thống kê với $p<0,05$. Tuy nhiên sự khác biệt về chỉ số BMI trung bình giữa hai giới không có ý nghĩa thống kê với $p>0,05$.

Tầm vóc của con người được quyết định trong giai đoạn tăng trưởng, tức là trong khoảng 25 năm đầu đời trong đó tiền dây thì là một trong giai đoạn rất quan trọng. Tốc độ tăng trưởng trong giai đoạn dậy thì có thể đóng góp 15 - 25\% chiều cao lúc trưởng thành của môt cá thể.

Kết quả nghiên cứu của chúng tôi tương đồng với kết quả nghiên cứu của tác giả

Trần Thi Minh Hanh tại Thành phố Hồ Chí Minh (2012) ở học sinh thành phố Hồ Chí Minh [4] và nghiên cứu của tác giả Lê Trần Tuấn Anh, Nguyễn Thị Thắm và Cộng sự (2021) ở học sinh một số trường THPT tại Hải Phòng [4] đều cho thấy: Cân nặng và chiều cao trung bình của học sinh nam cao hơn so với họ sinh nữ.

Khi so sánh chiêu cao với một số nước trong khu vực thì chiều cao trung bình của học sinh trong nghiên cứu của chúng tôi cao hơn so với chiêu cao của thanh niên Indonesia, tương đương so với Malaysia và Thái Lan, tuy nhiên thấp hơn so với các nước như Hàn Quốc, Nhật Bản, điều này cho thấy chiều cao của trẻ vị thành niên Việt Nam vẫn còn khiêm tốn so với một sỗ nước trong khu vực cũng như trên thế giới.

Kết quả nghiển cứu của chúng tôi ở bảng 3.3 cho thấy: Tỷ lệ học sinh bị suy dinh dưỡng thấp còi chiếm khá cao $12,7 \%$ trong đó suy dinh dưỡng mức độ vừa chiếm chủ yếu $12,0 \%$, suy dinh dưỡng mức độ nặng chỉ chiếm tỷ lệ $0,7 \%$ trong đó suy dinh dưỡng thấp còi mức độ vừa và nặng ở nữ học sinh $(12,2 \%$ và $0,8 \%)$ cao hơn nam học sinh $(11,7 \%$ và $0,5 \%)$, tuy nhiên sự khác biệt không có ý nghĩa thống kê giữa tỷ lệ suy dinh dưỡng thể thấp còi giữa hai giới $(p>$ 0,05 ). Kết quả nghiên cứu của chúng tôi cao hơn so với kết quả nghiên cứu của tác giả Lê Trần Tuấn Anh, Nguyễn Thị Thắm và Cộng sự (2021) ở học sinh PTTH tại Hải Phòng: Tỷ lệ học sinh bị suy dinh dưỡng thể thấp còi của học sinh Trung học phổ thông Lê Quý Đôn là 6,4\% trong đó ở nam là $6,1 \%$, ở nữ là $6,6 \%$. Nhưng kết quả của chúng tôi tương đồng với kết quả nghiên cứu của Trần Thị Minh Hạnh (2012) tại Thành phố Hồ Chí Minh: Tỷ lệ suy dinh dưỡng thể thấp còi ở nhóm đối tượng học sinh phổ thông trung học là $10,7 \%$ [4].

Tỷ lệ suy dinh dưỡng thấp còi còn ở mức cao có thể do suy dinh dưỡng từ nhỏ, do yếu tố di truyền hoăc nhu cầu dinh dưỡng trong giai đoan vừa qua chỉ đáp ứng được nhu cầu tăng cẩn nặng mà không đáp ứng được sự phát triển chiều cao.

Tỷ lệ suy dinh dưỡng thể gầy còm của hoc sinh trong nghiên cứu của chúng tôi chiếm $6,9 \%$. Học sinh nữ $(7,5 \%)$ có tỷ lệ suy dinh dưỡng cao hơn học sinh nam $(6,1 \%)$ (bảng 3.4). Kết quả nghiên cứu của chúng tôi tương đồng với kết quả nghiên cứu của tác giả Nguyễn Nhật Cảm, Nguyễn Thị Thi Thơ và cộng sự (2016) cho thây: Tỷ lệ suy dinh dưỡng thể gầy còm ở hoc sinh từ 11- 17 tuổi là 7,59\% trong đó suy dinh dưỡng gây còm nặng là 1,85\%, và tỷ lệ suy dinh dưỡng thể gầy còm vừa là 5,74\% [2].

Tỳ lê thừa cân, béo phì ở học sinh trong nghiên cứu của chúng tôi chiếm 13,8\% trong đó tỷ lệ thừa cân, béo phì ở học sinh nam $(17,9 \%)$ cũng cao hơn rõ rệt học sinh nữ $(10,6 \%)$ (bảng 3.4). Kết quả nghiên cứu của chúng tôi thấp hơn kết quả nghiên cứu của tác giả Nguyễn Thị Thắm, Lê Trần Tuấn Anh và cộng sự (2021) về tỷ lệ thừa cân, béo phì ở cả hai giới nhưng đều cho thất tỷ lệ thừa cân, béo phì ở học sinh nam cao hơn học sinh nữ: Tỷ lệ TCBP ở hoc sinh là $17,3 \%$, trong đó thừa cân là $14,0 \%$, béo phì là $3,3 \%$. Tỷ lệ TCBP ở học sinh nam $25,2 \%$ cao hơn so với học sinh nữ $11,1 \%$ [5].

Có nhiều nguyên nhân gây thừa cân, béo phì nhưng chủ yếu là ăn uống không hợp lý (thức ăn nhanh, nước ngọt, bánh ngọt, bim bim...) và ít vận động. Thời gian hoạt động thể lực trong ngày của trẻ em đang giảm trong khi thời gian tĩnh tại (gồm chơi game, xem TV, học thêm...) lại tăng một cách rõ rêtt. Ngoài ra, những trẻ có bố me bị thừa cân, béo phì có nguy cơ bị thừa cân, béo phì cao hơn những trẻ có bố mẹ không bị thừa cân, béo phì.

\section{KẾT LUÂN}

- Tỷ lệ học sinh bị suy dinh dưỡng thể thấp còi chiếm khá cao 12,7\%: Suy dinh dưỡng mức độ vừa chiếm chủ yếu $12,0 \%$, suy dinh dưỡng mức độ nặng chỉ chiếm tỷ lệ 0,7\%.

Tỷ lệ suy dinh dưỡng thấp còi ở học sinh nữ $(13,0 \%)$ cao hơn học sinh nam $(12,2 \%)$, tuy nhiên sự khác biệt không có ý nghĩa thống kê giữa tỷ lệ suy dinh dưỡng thể thấp còi giữa hai giới $(p>0,05)$.

- Tỷ lệ suy dinh dưỡng thể gầy còm của học 
sinh chiếm $6,9 \%$. Học sinh nữ $(7,5 \%)$ có tỷ lệ suy dinh dưỡng cao hơn học sinh nam $(6,1 \%)$.

- Tỷ lệ thừa cân, béo phì chiếm 13,8\%. Trong đó tỷ lệ thừa cân, béo phì ở học sinh nam $(17,9 \%)$ cao hơn rõ rệt ở học sinh nữ (10,6\%).

\section{KHUYẾN NGH!}

- Tăng cường các biênn pháp can thiêp nhằm cải thiện tình trạng dinh dương cho trè em lứa tuổi học đường nói chung và lứa tuổi học sinh trung học phổ thông.

- Cân xây dựng chế độ ăn cân đối, hợp lý đảm bảo cung cấp đủ các chất dinh dưỡng sinh năng lượng (protein, lipid và glucid) và không sinh năng lượng (vitamin và chất khoáng) cho các em học sinh.

\section{TÀI LIÊU THAM KHẢO}

1. Lê Trân Tuấn Anh, Nguyễn Thị Thắm, Nguyễn Đức Dương, Nguyền Quang Hùng (2021), Thực trạng suy dinh dưỡng thể thấp còi và một số yếu tố liên quan ở một số trường trung học phổ thông tại Hải Phòng năm 2019, Tạp chí Y học dự phòng tập 31 , số 1 , tr. 66 - 71 .

2. Nguyện Nhật Cảm, Nguyễn Thị Thi Thơ, Nguyển Thi Kiêu Anh (2017), Tỷ lê suy dinh dưỡng thể gày còm và một số yêu tố liên quan của học sinh từ 11 - 17 tuổi tại thành phố Hà Nội, Tạp chí Y hoc dư phòng, tâp 27, số 7, tr. 120 - 12'9.

3. Lê Thị Hợp, Huỳnh Nam Phương (2011), Thống nhất về phương pháp đánh giá tình trạng dinh dưỡng bằng nhẩn trắc học, Tạp chí Dinh dưỡng và Thực phẩm, 7(2) tr. 28 - 29 .

4. Trân Thị Minh Hanh, vũ Quỳnh Hoa và Đỗ Thi Ngoc Diệp (2012), Diễn tiến tình trạng dinh dưỡing và tăng trướng hoc sinh Tp. HCM 20022009, Tạp chí Dinh dưỡng và Thực phẩm; 8(4): tr. $17-26$.

5. Nguyễn Thị Thắm, Lê Trân Tuấn Anh, Nguyễn Đức Dương, Hoàng Thị Giang, Nguyến Quang Hùng (2021), Thực trạng thữa cân, béo phì và một số yếu tô liên quan ở học sinh một số trường phổ thông trung học tai Hải Phòng năm 2019 2020, Tạp chí Y học dự phòng, tập 31, sô 1, tr. 148 - 154.

\title{
PHÂN TíCH KIẾN THỨC, THÁI ĐỘ VÀ THƯC HÀNH CỦA NHÂN VIÊN Y TẾ VỀ BÁO CÁO PHẢN ỨNG CÓ HẠI CỦA THUỐC TẠI MộT SỐ BỆNH VIÊ̂N ĐA KHOA NĂM 2020
}

\author{
Trần Thị Lan Anh ${ }^{1}$, Trần Lê Vương Đại ${ }^{2}$, Vũ Phương Thảo ${ }^{1}$, \\ Trần Ngân Hà ${ }^{1}$, Bùi Thị Ngọc Thực ${ }^{2}$, Nguyễn Thu Minh ${ }^{2}$, \\ Nguyễn Quỳnh $\mathrm{Hoa}^{2}$, Nguyễn Hoàng Anh ${ }^{1,2}$. Trần Nhân Thắng ${ }^{2}$
}

\section{TÓM TẮT}

Mục tiêu: Nghiên cứu được thực hiện tại 3 bệnh viện đảa khoa ở những vùng địa lý khác nhau với cơ cấu tổ chức và triển khai hoạt động Cảnh giác Dược ở các mức độ khác nhau nhằm phân tích thực trạng kiến thức, thái độ và thực hành của NVYT về hoạt động báo cáo phản ứng có hại của thuốc. Đối tượng và phương pháp nghiên cứu: Nghiên cứu mồ tả cắt ngang, thu thập thông tin kiến thức, thái độ và thực hành của NVYTं về báo cáo $A D R$ thông qua phỏng vấn bằng bô câu hỏi, được thu thâp từ tháng 10 đến tháng 11 năn 2020. Kết quả: Hầu hết nhân viên y tế đều có kiến thức đầy đủ vê $A D R$ và cơi hoạt động báo cáo ADR là một trong những hoạt động chuyên môn quan trọng. Mặc dù có $73,48 \%$ NVY̛T đã từng gặp ADR song chỉ có 49,08\% NVYT đã từng báo cáo ADR. Hơn $40 \%$ số NVYT khảo sát không biết báo cáo và không báo cáo các phản ứng nhẹ. Kết luận: Phần lớn

${ }^{1}$ Trường Đại học Dược Hà Nội

${ }^{2}$ Khoa Dước, Bênh viên Bach Mai

Chịu trách nhiệm chính: Trần Thị Lan Anh

Email: tranlananh7777@gmail.com

Ngày nhận bài: 4.3.2021

Ngày phản biên khoa hoc: 26.4 .2021

Ngày duyệt bài: 7.5.2021 các NVYT có thái độ và kiến thức tốt về báo cáo $A D R$ song tỷ lê báo cáo vẫn còn thấp. Đào tao tâp huấn về $A D R$ và kết hợp nhiều hình thức báo cáo là giải pháp để nâng cao hiệu quả hoạt động boá cáo ADR.

\section{SUMMARY \\ KNOWLEDGE, ATTITUDE AND PRACTICES (KAP) OF HEALTHCARE PROFESSIONALS IN THREE GENERAL HOSPITALS TOWARDS ADVERSE DRUG REACTION (ADR) REPORTING IN 2020}

Objective: The purpose of this study was to analyze the knowledge, attitudes, and practices of healthcare professionals (HCPs) towards adverse drug reaction reporting in three general hospitals. Methods: cross-sectional study was conducted from Oct to Nov 2020. Data were collected through selfadministered questionnaires with Google form. Results: Most HCPs have positive knowledge of ADR and consider ADR reporting to be one of the most important professional activities. Although $73.48 \%$ of HCPs have ever met ADR, only $49.08 \%$ have ever reported ADR. Of the respondents, over $40 \%$ did not know how to report and mild reactions that are not worth reporting, these are main factors contributing to non - reporting of ADRs. Conclusion: Most HCPs 